\title{
Categorização e Qualificação dos Queijos da Auvergne (França): Relações entre Expertise Científica e os Selos de Denominação de Origem ${ }^{1}$
}

\section{Categorization and Qualification of Cheeses from Auvergne (France): Connections between Scientific Expertise and the Certification Labels of Protected Designation of Origin}

\author{
Mayra Lafoz Bertussi \\ Centre Européen de Sociologie et Science Politique, Paris, França
}

\section{RESUMO}

$\mathrm{O}$ artigo reflete sobre as appellations d'origine contrôlée, uma das denominações de origem de maior reconhecimento na França. A inserção desse modelo para além do território francês, com o reconhecimento das appellations d'origine protégée junto à União Europeia e à Organização Mundial do Comércio, desencadeou uma série de controvérsias quanto à qualidade alimentar. $\mathrm{Na}$ Europa, concomitante à regulamentação dessa certificação para o conjunto de países membros, houve um incentivo para a solidificação da justificativa legal do estatuto privilegiado que as denominações de origem gozavam face às transações comerciais. Nesse contexto, foi estimulado um processo de legitimação dos selos via intensificação de critérios produtivos. Queijos fabricados a partir do leite cru foram qualificados como aqueles capazes de preservar a diversidade sensorial, gustativa e cognitiva do terroir. A partir do método etnográfico e de uma perspectiva dialógica, o presente artigo busca refletir sobre o trabalho de instituições científicas que, inseridas nesse contexto de legitimação das appellations d'origine contrôlée, trabalharam pela viabilidade sanitária dos queijos de leite cru. O objetivo, nesse caso, reside numa análise sobre a influência dos conhecimentos científicos na categorização e qualificação da produção alimentar. Como conclusão, o artigo observa

1 A pesquisa contou com uma bolsa de doutorado financiada pela Fundação de Amparo à Pesquisa do Estado de São Paulo (FAPESP), processo n 2017/04320-0, e com uma ajuda de custo recebida pelo LabEx-Tepsis/CESSP-EHESS. 
que, diferentemente dos casos em que o conhecimento científico é acionado para assegurar a inocuidade das inovações tecnológicas no mercado alimentar, a expertise científica se volta para a legitimação do que é considerado uma produção tradicional.

Palavras-chave: Denominações de origem, Construção social da qualidade, Expertise científica.

\section{ABSTRACT}

The article addresse on the appellations d'origine contrôlée, the most recognized certification of Protected Designation of Origin in France. The insertion of this model outside French territory, with the recognition of appellations d'origine protégée by the European Union and the World Trade Organization, triggered several controversies regarding food quality. In Europe, along with the regulation of this certification for all member countries, there was an incentive to strengthen the legal justification of the privileged reputation enjoyed by that the Protected Designation against trade transactions. In this context, a legitimizing process of the labels was encouraged by the intensification of production criteria. Cheeses made from raw milk were qualified as those capable of preserving the terroir's sensory, taste and cognitive diversity. Through the ethnographic method and a dialogical perspective, this article focuses on the work of scientific institutions inserted in this context of legitimizing appellations d'origine contrôlée, that have worked for health sustainability of raw milk cheeses. The goal in this case lies in an analysis of the influence of scientific knowledge on the categorization and qualification of food production. In conclusion, the article observes that, unlike the cases in which scientific knowledge is used to ensure the safety of technological innovations in the food market, scientific expertise is aimed at legitimizing what is considered traditional production.

Keywords: Protected designation of origin, Social construction of quality, Scientific expertise.

\section{SOBRE AS APPELLATIONS D'ORIGINE CONTRÔLÉE}

Os selos de denominação de origem são considerados uma das estratégias de patrimonialização da produção agroalimentar. Como uma estrutura de certificação, incidindo diretamente na categorização e classificação de produtos, as denominações de origem atuam na definição de quais artigos podem ou não fazer parte de um conjunto restrito e valorizado de mercadorias. Se comparados às commodities e aos produtos de consumo de massa, os bens agroalimentares 
de origem protegida se diferenciam por uma imagem de tipicidade e autenticidade ${ }^{2}$. Para tanto, as denominações de origem identificam procedência, insumos, instrumentos e métodos de fabricação como forma de operar uma reclassificação dos alimentos através de uma objetivação da distinção. Ideias como tradição, savoir-faire e autenticidade se associam a fim de criar a singularidade do produto protegido.

O interesse do presente artigo recai na denominação da origem mais difundida na França, as Appellations d'origines contrôlées (AOC). O pressuposto que guia a qualidade distintiva sustentada pelas AOC é a noção de terroir. Sem uma tradução exata para outras línguas, o terroir remete às especificidades geográficas, sociais e históricas do processo de produção de determinados bens agroalimentares. Assim, para que um produto possa gozar de um selo AOC, argumentos de cunho geográfico e social são engajados como forma de reconhecer sua autenticidade.

O modelo de certificação sustentado pelas AOC serviu de referência para disseminação das denominações de origem na construção do Mercado Comum Europeu. Enquanto a gênese das AOC data do início do século XX, com a institucionalização da proteção da origem para determinados vinhos franceses, o seu período de internacionalização remete aos anos 1990, quando tais selos já abarcavam uma diversidade de produtos agroalimentares, tais como azeites, manteiga e queijos. Inspirada pela política francesa de valorização de produtos agrícolas, a regulamentação europeia estabeleceu as Appellations d'origine protégée (AOP), um selo cuja concepção baseia-se, tal como as AOC, no vínculo do produto como seu terroir.

O objetivo deste artigo é compreender alguns dos mecanismos de categorização e qualificação da qualidade de queijos a partir das relações entre arcabouço normativo das denominações de origem, a pesquisa científica e o fomento das AOC. A relação entre a certificação dos queijos e o conhecimento científico é pertinente na medida em que a pesquisa de campo conheceu uma robusta estrutura científica, localizada na Auvergne, que atua na qualificação da produção de lácteos. A pesquisa de campo aponta que, diferentemente dos casos em que o conhecimento científico é acionado para assegurar a inocuidade das inovações tecnológicas no mercado alimentar, a expertise científica se volta para a legitimação do que é considerado uma produção tradicional.

Perseguindo as dinâmicas classificatórias que identificam a qualidade dos queijos sob o selo AOC, o presente artigo apresenta uma controvérsia que mobiliza parte dos interlocutores

2 Em francês, typicité e authenticité. Os termos ressaltados em itálico nesse artigo buscam reconhecer vocábulos franceses como também categorias nativas dos interlocutores da pesquisa. 
da pesquisa: o uso do leite cru para produção de queijos. Em linhas gerais, essa oposição é marcada, de um lado, pela compreensão de que existem queijos de leite cru que representam a expressão do seu terroir, já que a matéria-prima é capaz de singularizar o produto e representar o patrimônio gastronômico francês; de outro, os queijos de leite pasteurizado são encarados como padronizados, regulares e com menor incidência de risco sanitário. O pano de fundo dessa controvérsia tem na própria concepção de qualidade o seu ponto de referência: para alguns, a qualidade se refere ao gosto e à noção de terroir, enquanto para outros a qualidade tem um viés higienista e, portanto, o risco deve ser totalmente eliminado. Essa controvérsia torna-se ainda mais relevante porque mobiliza parte dos pesquisadores que dialogaram com a pesquisa. As disputas acerca do leite cru revelam, deste modo, alguns dos processos de categorização e classificação dos queijos da Auvergne.

\section{O CONTEXTO DA PESQUISA}

O trabalho apresentado é fruto de uma pesquisa iniciada em 2012, durante a realização do Mestrado em Anthropologie Sociale et Ethnologie na l'École des Hautes Études en Sciences Sociales (EHESS-França) e, posteriormente, aprofundada no doutorado na mesma disciplina e instituição. A partir de uma convenção de cotutela entre a EHESS e a Universidade Estadual de Campinas (UNICAMP), a pesquisa pôde aproveitar de maior circulação acadêmica e intercâmbio de ideias. O método privilegiado foi a etnografia e a perspectiva dialógica permitiu conhecer os diferentes argumentos e posturas dos interlocutores quanto aos critérios que conferem qualidade a um queijo.

A pesquisa de campo se concentrou principalmente na região da Auvergne ${ }^{3}$, durante os anos de 2012 a 2019. Localizada no Maciço Central francês, a Auvergne é uma região montanhosa que reúne cinco queijos de origem protegida: Bleu d'Auvergne, Fourme d'Ambert, Saint-Nectaire, Cantal e Salers. Embora abundem representações que vinculam esse território a uma identidade queijeira própria, é possível encontrar argumentos díspares a respeito da viabilidade desse espaço como lugar de prestígio na produção de queijos. Ainda que os selos AOC se configurem como uma demarcação da distinção, o grau de reconhecimento de cada selo da

3 A última reforma territorial e administrativa de 2015 nomeou a macrorregião como Auvergne-Rhône-Alpes. Contudo, as representações relacionadas à produção de queijos se referem frequentemente somente à Auvergne. $\mathrm{O}$ artigo mantém as categorias mais utilizadas pelos interlocutores da pesquisa. 
Auvergne é bastante desigual, o que reflete tanto em elogios quanto em críticas à região. Essa disparidade de prestígio entre os selos permitiu identificar os diferentes argumentos que sustentam a categorização dos queijos.

Para além dos organismos representativos dos produtores vinculados às AOC, a escolha pela Auvergne foi oportuna, pois os queijos da região são defendidos por uma verdadeira estrutura científica, sobretudo no que se refere à pesquisa, à formação e à análise da produção de leite e queijo. Entre as mais importantes estão : a École Nationale de 1'Industrie Laitière (ENIL); dois laboratórios profissionais, um destinado a análises da qualidade físico-química e microbiológica do leite e outro para o comércio de bactérias e leveduras; uma sede regional do Institut National de la Recherche Agronomique (INRA); e o Pôle Fromager AOC Massif central, uma associação cujo objetivo é realizar uma aproximação da pesquisa desenvolvida no local com as organizações representativas das $\mathrm{AOC}^{4}$. É pertinente ressaltar que a pesquisa de campo contou com a interlocução tanto de pesquisadores e cientistas vinculados à produção de queijos de qualidade quanto com produtores vinculados (ou não) aos selos AOC da Auvergne.

\section{A INSTITUCIONALIZAÇÃO DA QUALIDADE: 0 EXEMPLO DOS VINHOS E DO QUEIJO ROQUEFORT}

Um olhar sociológico sobre a construção da qualidade do vinho francês baseada na instituição das Appellations d'origine côntrolée oferece um referencial fundamental para relativização da qualidade sustentada pelas denominações de origem. No início do século XX, sob a Terceira República Francesa, o surgimento das AOC coincide com um período de disputas em torno das normas comerciais do mercado vitícola. Em meio a uma crise de superprodução, dois atores entram em concorrência. De um lado, os comerciantes que praticavam uma produção de caráter industrial e desterritorializada, com a mistura de vários componentes como açúcar e corantes; de outro, os proprietários dos vinhedos que, na busca pela valorização, sustentavam um modelo de produção artesanal e uma concepção natural do vinho. É pela perspectiva dos proprietários dos vinhedos que emerge a noção do terroir como princípio que atesta o vínculo entre origem geográfica e qualidade do vinho.

4 Em ordem de enunciação: Escola Nacional da Indústria de Lácteos e Instituto Nacional de Pesquisas Agronômicas (INRA). O tópico destinado à expertise científica aborda as atividades de algumas dessas entidades. 
Interessados pelas disputas a respeito da categorização e classificação da qualidade dos vinhos, o sociólogo Gille Laferté e o historiador Olivier Jacquet (2006) demonstram como as influências políticas dos proprietários dos vinhedos se revelaram progressivamente mais eficazes, desembocando na aprovação pelo Parlamento francês de uma lei em 1935 que institucionalizou as AOC. Como uma normatização do mercado a partir da noção de terroir, as AOC se configuram então como um sistema de classificação com grande intervenção do Estado, uma vez que ele institucionaliza o processo de proteção pela origem e detém o monopólio da concessão de tais selos. O reconhecimento da qualidade pela origem geográfica resultou numa hierarquia entre as áreas de produção, visto que os critérios de reconhecimento das AOC seguem preceitos da valorização do lugar e o princípio da raridade 5 .

Além do viés político e legislativo de institucionalização das AOC, evidente nesse período de regulamentação, Laferté (2006) lança mão de uma análise crítica para identificar o caráter simbólico que acompanhou esse processo de redefinição da qualidade dos vinhos. Nesse sentido, o autor evidencia as conexões político-culturais pelas quais os vinhos da Borgonha souberam reinventar a imagem do produto - de um bem aristocrático para um bem reconhecido como autêntico e vigneron ${ }^{6}$. Essa operação de renovação das estratégias comerciais do mercado de vinho é também decorrência de um processo de folclorização dos territórios vitícolas, resultado tanto do investimento no mundo turístico como do discurso universitário, quando se mobilizou acadêmicos regionais para produzir um discurso científico, legítimo e conforme as ambições comerciais das elites políticas e industriais da Borgonha (LAFERTÉ, 2006).

Para a presente análise, é relevante ressaltar como esferas inicialmente vistas como distantes, tais como o turismo e o discurso universitário, se engajaram no processo de redefinição da imagem dos vinhos da Borgonha. Nesse sentido, Laferté (2006) demonstra como o folclore e a gastronomia regional se transformaram em elementos centrais do repertório de ação turística empregado por grupos políticos e econômicos influentes na conversão da imagem da Borgonha. Se, inicialmente, a oferta de atrativos turísticos da região oferecia apenas monumentos e paisagens naturais, o período pós-guerra representa a incorporação da gastronomia como oferta turística. Tais empreendimentos institucionalizam um repertório de figuração dos territórios impulsionado inclusive pela economia vinícola (LAFERTÉ, 2006).

Se a sociogênese da qualidade dos vinhos da Borgonha e suas conexões com espaços de

5 A antropóloga Marie-France Garcia-Parpet (2009) mostra como o princípio da raridade desses produtos incide sobre a sua valorização.

6 A tradução literal de vigneron "é aquele que cultiva as videiras". Utilizado aqui como adjetivo, a categoria vigneron qualifica o vinho feito pelos proprietários dos vinhedos e ressalta um caráter artesanal do produto. 
valorização do mercado de vinho esclarecem as condições de difusão de uma imagem de excelência, a generalização das AOC para outros produtos além do vinho, assim como a multiplicação de denominações de origem com base nos princípios do modelo francês, revela sua eficácia. O exemplo dos vinhos demonstra que, como em tantos outros processos sociais, a qualidade alimentar é resultado de processos de categorização e qualificação que respondem a contextos historicamente datados, socialmente e economicamente situados.

No que concerne à produção de queijos, a primeira AOC é instituída para o Roquefort com a promulgação de uma lei em 1925. Diferentemente da maioria dos selos AOC que se sucederam, esse primeiro selo não estabeleceu uma zona geográfica de produção de leite e queijo, mas protegeu suas cavernas de maturação e determinou o leite de ovelha como matéria-prima obrigatória. Após a Primeira Guerra Mundial, o mercado do Roquefort sofreu uma queda na produção de leite de ovelha e foi afetado com sucessivas falsificações oriundas de regiões vizinhas e de outros países. A redução na quantidade de leite levou produtores a fabricarem queijos de leite de vaca sob o nome de Roquefort, além de misturarem leite de ovelha com o de vaca e cabra. Os proprietários das $\operatorname{caves}^{7}$ compravam queijos de leite de vaca fresco para maturar em cavernas chamadas de bastardas $^{8}$ e os identificavam como Roquefort, fazendo com que parte dos produtos vendidos sob esse nome não passasse pelas caves naturais do Combalou.

Produtores de leite, por sua vez, se preocupavam com a possibilidade de industriais expandirem a área de coleta de queijos frescos para as colônias da África do Norte, enquanto os industriais suspeitavam da qualidade do leite fornecido pelos produtores de leite ${ }^{9}$. Três eram então os critérios que geravam conflito: a interdição do leite de vaca, a extensão territorial das caves e o raio de coleta do leite. O primeiro tornou-se mais facilmente consensual, o leite de ovelha foi tornado obrigatório. A delimitação geográfica das caves foi um ponto sensível, uma vez que a questão recaía sobre a inclusão daquelas consideradas bastardas para a produção do Roquefort.

7 As caves são um espaço onde temperatura e umidade do ar são controladas para armazenamento dos queijos durante o período de maturação. Para o momento histórico em questão, as caves do Roquefort eram cavernas naturais destinadas à maturação do queijo.

8 Em francês, caves bâtardes. Sylvie Vabre (2015) menciona uma tentativa de legalização dessas caves bastardas no final do século XIX. A investida não deu certo, mas sem dúvida a extensão do território das caves é mais um elemento de disputa na definição do produto.

9 À medida que o mercado do queijo Roquefort se expandia, proprietários das caves ampliavam a compra de queijos frescos para além da região Roquefort trazendo-os para maturá-los em suas cavernas. A maturação tornou-se, dessa forma, um processo localizado no Roquefort enquanto a produção do leite era realizada em regiões diversas. A extensão das áreas de coleta do queijo responde igualmente à necessidade de ampliar o tempo de fabricação, uma vez que o período de ordenha das ovelhas na região do Roquefort se limitava aos meses de fevereiro a março e junho a julho. 
O tópico mais interessante tem a ver com a procedência do leite. Mesmo havendo uma proposta de limitação geográfica das áreas de produção, que buscava restringir o raio de coleta para as regiões do Aveyron, Lozère, Gard e Hérault, esse projeto não foi aceito. A mais importante empresa do Roquefort, a Société des caves, fazia algumas prospecções nas colônias do Norte da África, estendendo a área de busca de queijos brancos para essas localidades.

Depois de alguns embates, foi decidido que a origem do leite deveria ser proveniente da França continental e da Córsega ${ }^{10}$, uma extensão bastante ampla se comparada aos selos subsequentes. A ênfase da AOC no Roquefort parecia residir nas caves de maturação e não na delimitação de uma zona de produção do leite, critério que se tornou elementar nos selos que se sucederam. Essa comparação fica ainda mais evidente se levarmos em consideração que, no final dos anos de 1990, momento de internacionalização dos selos AOC, a qualidade do leite é compreendida como atrelada à sua área de produção. Portanto, o caso do primeiro queijo AOC demonstra o quanto a definição do terroir não é dada a priori, mas resultado de processos sociais e econômicos de categorização que refletem tanto as disputas pela qualificação do produto quanto as influências políticas daqueles que conseguem impor seus interesses nesta delimitação.

Após o reconhecimento do Roquefort, outros selos destinados à salvaguarda da produção de queijos foram instituídos pela via judicial. Somente em 1955 foi promulgada uma legislação específica para queijos, posto que as primeiras AOC foram elaboradas para a realidade dos vinhos e atribuídas somente a eles. Somente nos anos de 1990 que o selo AOC é reconhecido por todo o território europeu através da instituição do selo AOP. O próximo tópico se concentra neste processo de internacionalização do selo, sendo que o período traz uma série de controvérsias quanto à categorização da qualidade dos queijos.

\section{A INTERNACIONALIZAÇÃO DAS AOC PARA 0 TERRITÓRIO EUROPEU}

Um dos recortes históricos oportunos neste artigo diz respeito à internacionalização dos

10 Estabelecidos na Córsega desde 1893, os industriais do Roquefort coletavam quase toda a produção de leite de ovelha da ilha. No final da década de 1970, ao se depararam com o excesso de leite em relação à demanda, devido à intensificação da produção na região do Aveyron, os industriais decidiram parar de fazer Roquefort na Córsega. A denominação de origem do queijo Brocciu surgiu como uma forma de reconhecer produtores que historicamente estavam vinculados à produção do Roquefort. 
selos AOC. Os momentos de expansão do comércio são espaços privilegiados para acompanhar as disputas e controvérsias relativas à categorização dos bens.

Um dos marcos da normatização da produção alimentar é a rodada de negociação do Acordo Geral sobre Pautas Aduaneiras e Comércio (GATT), realizada no Uruguai em 1987, que incluiu os produtos agrícolas e alimentares dentro de seus compromissos multilaterais. Convenções bilaterais entre países continuaram sendo acolhidas, mas essa inclusão representou uma ampliação da normatização internacional no setor, posto que o GATT tem papel central na diminuição de barreiras comerciais entre países.

No que tange aos produtos de origem protegida, o GATT integrou as indicações geográficas (IGs), categoria que abrange diferentes selos de procedência, enquanto direito de propriedade intelectual, fazendo que tal arcabouço legal fosse incluído no Acordo sobre Aspectos Relacionados ao Comércio de Direitos de Propriedade Intelectual (TRIPS). A rodada do Uruguai culminou então com a criação da Organização Mundial do Comércio (OMC), em janeiro de 1995, que sucedeu ao GATT na regulação do mercado mundial.

Tanto a criação da OMC quanto o Acordo TRIPS fizeram com que os países incorporassem um novo padrão de propriedade intelectual em suas legislações nacionais, criando mecanismos de penalização para os Estados-membros que não cumprissem tais acordos. As IGs, categoria citada no Acordo, sofreram pressões para comprovação de sua credibilidade, sobretudo por países como os Estados Unidos, onde os princípios da economia liberal baseiam-se essencialmente na propriedade individual. As IGs, por outro lado, representam uma outra concepção de propriedade, já que protegem um bem de acordo com seu território de origem. A socióloga Elizabeth Barham (2003, p. 129, tradução nossa) ${ }^{11}$ descreve bem essa oposição americana:

Num nível mais profundo, as indicações geográficas como um tipo de propriedade intelectual desafiam o direito, a cultura e a lógica econômica do comércio norte-americano, orientado pela teoria econômica liberal baseada na propriedade individual. Os Estados Unidos estão familiarizados e se sentem à vontade com as marcas registradas (trademarks) como uma forma de proteger a propriedade intelectual associada ao nome de uma empresa.

Num certo sentido, e porque relacionada a um espaço geográfico, as IGs representam um tipo de propriedade coletiva. A Organização Mundial da Propriedade Intelectual (OMPI)

11 On a deeper level, geographical indications as a form of intellectual property challenge the law, culture and economic logic of American business, oriented as it is towards liberal economic theory based on individual ownership. The United States is familiar and comfortable with trademarks as a way of protecting the intellectual property associated with a business name. 
reconheceu a posição ímpar ocupada pelas indicações geográficas no comércio mundial e criou um comitê especial dedicado ao desenvolvimento de uma melhor compreensão de como elas funcionam enquanto direito de propriedade intelectual. Os litígios a respeito de diferentes concepções de propriedade ficam mais evidentes se levarmos em conta que organismos como a OMC e acordos como o TRIPS sustentam em seu arcabouço teórico uma economia liberal, buscando como ideal um mercado sem atrito, ou seja, um modelo que nada impeça o livre fluxo de mercadorias, capital e trabalho. As IGs tornaram-se, para determinados países, um empecilho ao modelo baseado na propriedade individual. Os Estados Unidos são o exemplo paradigmático dessa postura.

Frente às negociações internacionais com a OMC, a União Europeia (UE) tomou uma postura em defesa das IGs se municiando para enfrentar a referência americana fundamentada no modelo de propriedade individual. Contudo, antes da chegada desse consenso pelas IGs, uma controvérsia quanto à qualidade dos produtos agroalimentares delimitou duas posições antagônicas. De um lado, países do sul da UE se situaram em favor do reconhecimento do sistema de proteção da origem e, de outro, países do norte se posicionaram na defesa de um modelo de uniformização da produção em que a tônica está na padronização e numa abordagem sanitária que privilegia a ausência de risco. Não por acaso, os países do sul, como França, Itália e Espanha, acumulam entre si o maior número de bens beneficiados por tais selos ${ }^{12}$. A França tornou-se, de certa maneira, a representante desse núcleo, sendo que o país acumula duas mercadorias com interesse comercial nos selos - os vinhos e os lácteos, em especial, os queijos.

No relatório de um programa de pesquisa realizado pelo INRA (CASABIANCA; VALCESCHINI, 1996), uma seção é destinada ao quadro institucional que dá sustentação à salvaguarda das denominações de origem pela UE. É significativo notar que a controvérsia identificada acima é citada nesse relatório da seguinte forma: o bloco de países a favor dos selos é chamado de "Europa do paladar"13, numa alusão ao seu papel de referência na gastronomia, enquanto os países do norte são qualificados pela abordagem tecnocrática do produto.

Um lado é visto como subjetivo e cultural, o outro é industrial e objetivo. Há divergências também no que concerne à inovação, tema caro aos estudos sobre produção agroalimentar. Estados do norte a compreendem como um processo tecnológico que diminui custos, enquanto os países do sul rejeitam que ela possa limitar a valorização do patrimônio agrícola e alimentar.

12 França e Itália são os dois principais países da UE em termos de valor de vendas sob IG e em número de produtos beneficiados, alcançando $52 \%$ do total de IGs só nos dois países. Para mais informações, ver: https://www. wipo.int/edocs/mdocs/geoind/en/wipo_geo_bud_15/wipo_geo_bud_15_8-annex1.pdf. Acesso em: 20 out. 2020.

13 “Europe des Papilles” (CASABIANCA; VALCESCHINI, 1996, p. 243). 
A inovação, segundo essa última vertente, não deve ameaçar um produto tradicional (CASABIANCA; VALCESCHINI, 1996).

Os autores do relatório ainda trazem como exemplo os dissensos relativos aos queijos de leite cru e o papel preponderante da França neste cenário. A harmonização ${ }^{14}$ de regras sanitárias foi um ponto crucial para a diminuição de barreiras para o livre comércio na UE. No contexto de internacionalização dos selos de denominação geográfica e, para o caso específico dos produtos lácteos, os queijos de leite cru tornaram-se então um emblema.

Dois campos se configuraram, um que apela para o viés higienista, enquanto outro visa garantir a diversidade do gosto e de terroirs. Nessa situação específica, segundo os autores do relatório, houve um apelo popular e uma petição pública intitulada "Sauvons nos fromages"15 foi endereçada ao Ministério da Agricultura em 1992 para solicitar uma intervenção na Comissão Europeia em favor dos queijos de leite cru. Para certos especialistas e críticos gastronômicos franceses, os queijos de leite cru se tornaram um dos fundamentos da identidade nacional, sendo o seu carácter cultural e patrimonial argumentos para proteção. Estabeleceu-se, nesse momento, um paralelo por parte da opinião pública que vinculava queijos de leite cru às AOC, apesar de que, na prática, nem todos os queijos de origem protegida são exclusivamente de leite cru.

O leite cru acaba por ser aceito em toda UE. Uma diretiva instituída em 1992 estabelece as regras sanitárias para a produção e comercialização de lácteos de leite cru e tratados termicamente ${ }^{16}$. Uma série de outras diretivas se seguem quando, em 2006, a harmonização dos regulamentos sanitários europeus para produção e comercialização de produtos alimentares se completou com a instituição do chamado "Pacote Higiene"17. Ainda que tenha sido uma regulamentação adotada por todos os países membros, os argumentos da controvérsia se mantiveram - de um lado, higienistas sustentam uma noção de qualidade como a ausência de bactérias patógenas; de outro, a qualidade é vista pelo viés da tipicidade, ou seja, enquanto um bem patrimonial inculcado pelo vínculo do produto com seu terroir.

Durante a pesquisa de campo, realizada mais de 10 anos depois do estabelecimento deste

$14 \mathrm{O}$ verbo harmonizar é bastante utilizado em textos oficiais que estabelecem recomendações e diretivas no âmbito do comércio agroalimentar. Como parte de meus interlocutores de pesquisa também se valem de tal categoria, sobretudo pesquisadores e experts do mercado de queijo, preferi ressaltá-la em itálico.

15 "Salvemos nossos queijos". (CASABIANCA; VALCESCHINI, 1996, p. 245).

16 Directive 92/46/cee du conseil du 16 juin 1992.

17 Paquet Hygiène. Para mais informações, ver: https://www.anses.fr/fr/content/le-paquet-hygiène. Acesso em: 20 out. 2020 . 
marco regulatório, parte dos interlocutores, sobretudo aqueles que sustentam a singularidade dos "produtos de terroir", compreende o "Pacote Higiene" como um rol de normativas sanitárias que incentivaram a homogeneização da produção de queijos. Nessa perspectiva, o "Pacote Higiene" não respeitou a diversidade dos queijos de terroir e causou um empobrecimento na microflora dos queijos, afetando sua qualidade sensorial.

Esse contexto institucional de internacionalização das AOC reanimou a oposição acerca da qualidade dos queijos. De um lado, os partidários de uma produção padronizada que não incida em riscos sanitários e, de outro, os defensores da preservação daquilo que é compreendido como um patrimônio cultural gastronômico. Embora antagônica em termos argumentativos, essa oposição é muito mais complexa na prática, pois um só produto pode conjugar essas concepções em determinadas situações no mercado e nas legislações correspondentes ${ }^{18}$.

\section{OS REFLEXOS DA INTERNACIONALIZAÇÃO DAS AOC E A BUSCA PELA LEGITIMIDADE DO TERROIR}

A internacionalização dos selos de indicação geográfica se refletiu em controvérsias relativas à qualidade alimentar. Resistências foram travadas tanto no debate mundial, a exemplo das discussões na OMC, quanto no território europeu, durante o estabelecimento do mercado comum. Na Europa, concomitante à regulamentação da certificação para o conjunto de países membros, houve um incentivo para a solidificação da justificativa legal do estatuto privilegiado que as IGs gozavam face às transações comerciais. Autoridades europeias insistiram sobre a importância em desenvolver estratégias ofensivas suscetíveis de reforçar a argumentação dos seus negociadores em prol de tais selos. Dentro dos parâmetros do livre mercado, era preciso comprovar que as denominações de origem não se tratavam de uma competição injusta. Buscou-se, dessa forma, fundamentos de consolidação e legitimação desse instrumento.

Nos anos 90, ao regulamentar as IGs para o conjunto dos seus estados membros, a UE deixou sob a responsabilidade de cada estado-nação a administração dessa certificação. $\mathrm{Na}$ França, esse período coincidiu com a extensão das competências do Institut national de l'origine et qualité (INAO), que originalmente se responsabilizava apenas pelas denominações vinícolas

18 Para mais informações a respeito das controvérsias sobre a qualidade alimentar e dos diferentes processos de categorização dos queijos, ver Bertussi, 2020. 
e passou a assumir o controle de todos os produtos protegidos pelas indicações geográficas ${ }^{19}$.

Essa extensão das competências, conhecida também como um período de "reforma do INAO", é relevante, pois fez com que outros produtos pudessem gozar de uma estrutura de proteção semelhante àquela usufruída para o vinho. Como reforça a geógrafa Claire Delfosse: "Foi necessário aguardar a reforma das AOC de 1990 para que o queijo fosse realmente considerado igual ao vinho no que se refere à sua proteção de sua origem" (DELFOSSE, 1995, p. 206, tradução nossa $)^{20}$.

A experiência de campo com o responsável pela delegação da região Auvergne-Limousin do INAO é eloquente do posicionamento do instituto em favor das AOC durante esse momento político. Ele reconhece que o INAO, representando todos os selos de denominação de origem frente à União Europeia, busca realizar um projeto de "tradução do terroir". Os fundamentos da propriedade intelectual serviram como argumento de proteção e, como justificativa para tal defesa, foi necessário incentivar um endurecimento nos critérios de produção dos queijos AOC. Nesse sentido, para que consiga defender tais selos nas negociações europeias, bem como para o restante do mundo, o INAO encaminha determinadas exigências às AOC. Assiste-se, então, a um movimento massivo de revisão das normas de produção, incentivado principalmente pelo INAO, mas igualmente por um conjunto de pesquisadores, profissionais do setor e agricultores que partilham da ideia de que os AOC devem ser um instrumento de garantia do terroir. Para identificar esse período, o responsável regional do INAO utiliza a categoria de "densificação nos cadernos de especificações técnicas”"21 (DIÁRIO DE CAMPO, 2015).

Esse movimento de densificação fica mais perceptível se comparado com os primeiros cadernos de especificações técnicas, o que na região da Auvergne remonta as décadas de 50 e 60. Enquanto as primeiras normas se limitavam essencialmente à proteção do nome e delimitação de uma zona geográfica de produção, sobretudo para reprimir as falsificações que se aproveitavam do renome dos queijos franceses para comercializar produtos oriundos de outros países, esse período de densificação traz novos critérios à cena: a delimitação de raças bovinas tidas como tradicionais; a valorização do capim e do feno como ração de base e a interdição da alimentação fermentada para as vacas; o uso preferencial do leite cru como argumento de pre-

19 O INAO tornou-se o responsável pelo conjunto de todos os selos oficiais de qualidade (AOC/AOP, IGP, Agricultura Orgânica, Label Rouge).

20 Il faudra attendre la reforme des AOC de 1990 pour que le fromage soit vraiment considéré comme l'égal du vin pour la protection de son origine.

21 Cahiers des charges. Os cadernos de especificações técnicas são um conjunto de normas específicas para cada produto $\mathrm{AOC}$ e que, ao menos idealmente, representa a garantia de um vínculo intrínseco entre o produto e seu terroir. Os cadernos de especificações técnicas são estabelecidos por decreto. 
servação da diversidade sensorial, gustativa e cognitiva do terroir; e ainda, a extensão do tempo de maturação dos queijos como garantia de melhor gosto e qualidade.

Como uma espécie de taxonomia, tais critérios se tornaram balizas para classificar a produção de queijos de origem reconhecida na França. Dessa forma, adequar-se a tais normas é visto como um respeito a origem e ao terroir. Tais normas criaram um registro cujos termos visam refletir essencialmente a autenticidade e a singularidade dos queijos de origem reconhecida. Ainda que o conceito de terroir sustente, antes de tudo, uma forma de unicidade de cada produto, tais critérios tornaram-se referências nacionais.

Para melhor compreender esse movimento de densificação de critérios produtivos é preciso contextualizar os selos de denominação de origem dentro das estratégias de patrimonialização da produção alimentar. A mais recente obra dos sociólogos Luc Boltanski e Arnaud Esquerre, L'enrichissement: Une critique de la marchandise (2017), oferece pistas para pensar mecanismos sociais contemporâneos de determinação do valor a certos bens. Considerando o valor como uma justificativa ou crítica do preço das coisas, os sociólogos chamam a atenção para um processo em que determinados objetos ou coisas alcançam um grau de distinção que está menos vinculado à sua utilidade e mais relacionado a uma espécie de preciosidade intrínseca, o que faz com que tais objetos se diferenciem dos demais. Buscando caracterizar mudanças significativas do capitalismo nos últimos 30 anos, influenciadas, entre outros, pelo processo de desindustrialização, os autores identificam formas contemporâneas da mercantilização e da formação do preço em países europeus. Embora tais formas de exploração de recursos não sejam absolutamente novas, elas encontram respaldo crescente no mercado de arte, na economia do luxo, no turismo e em processos de patrimonialização.

Batizada como uma économie de 1'enrichissement ${ }^{22}$, esse modo de produção de valor se constitui como uma maneira particular de valorização das coisas a partir da exploração de determinados detalhes específicos acumulados ao longo do tempo e exaltados numa narrativa própria. Uma das características desse modelo reside na criação de uma narrativa na qual métodos e processos provenientes do modelo industrial devam ser afastados. A economia que se baseia no enriquecimento das coisas produz uma imagem interessada em se distinguir da produção em larga escala, de produtos destinados a serem rapidamente consumidos e/ou que se caracterizem por ser de gosto popular.

Um olhar acurado para os critérios produtivos propalados durante o período de densificação dos cadernos de especificações técnicas percebe que as práticas exaltadas buscam,

22 Economia do enriquecimento (BOLTANSKI; ESQUERRE, 2017). 
de certa maneira, se diferenciar daquelas usadas regularmente nos processos industriais. Por exemplo, as raças bovinas consideradas tradicionais produzem frequentemente menor quantidade leite se comparada com aquelas incentivadas durante a especialização do gado leiteiro. $\mathrm{O}$ uso do capim e feno como ração de base, no lugar da ensilagem, também incide na quantidade de leite que cada animal é capaz de produzir. O leite cru, embora possa ser fabricado em grandes volumes, também se torna um empecilho em determinadas tecnologias queijeiras que visam a produção em larga escala.

Ainda que o afastamento de métodos industriais seja apenas uma das estratégias deste mecanismo social de determinação do valor reconhecido por Boltanski e Esquerre (2017), algumas das discussões a respeito dos queijos de leite cru na França podem ser observadas por essa perspectiva. O modelo descrito pelos autores preza pela importância dada não apenas aos objetos, mas ao universo em que esses objetos são concebidos e circulam. Assim, ganham destaque as pessoas presentes ao redor dos objetos valorizados, tais como "criadores", estilistas, cozinheiros, produtores, colecionadores, crémiers-fromagers etc ${ }^{23}$.

Como representativo do que é o bom gosto para especialistas no universo dos queijos, o leite cru é um dos ingredientes que confere singularidade aos produtos. Tal classificação está longe de ser aleatória, pois dela participa todo um conjunto de mediações, nas quais determinadas instituições e personalidades gozam de legitimidade para orientar o consumo daquilo que pode ser considerado como autêntico queijo de terroir. Como parte desse espaço legítimo de enunciação do "bom gosto", a fala de Laurent Dubois, um renomado maître-fromager ${ }^{24}$ cujas propriedades somam hoje quatro queijarias em bairros nobres de Paris, mostra o valor do leite cru enquanto matéria-prima de excelência:

O leite cru é revelador do terroir, pois não sofre nenhum tratamento térmico e, portanto, atesta a verdade gustativa, verdadeiro reflexo da adaptação do animal ao solo e, por outro lado, os métodos de fabricação desenvolvidos ao longo dos anos pelos homens. O processamento do leite cru é muito sensível e não suporta a mediocridade. Oferece um sabor incomparável e uma profunda riqueza aromática ${ }^{25}$ (DUBOIS, 2020, on-line, tradução nossa).

23 Para conhecer algumas das narrativas utilizadas na venda direta de queijos que auxiliam nesse processo de enriquecimento das coisas, ver BERTUSSI (2020).

24 Maître-fromager é uma das denominações utilizadas para alguém com reconhecido conhecimento na transformação de leite em queijo e na sua maturação. Tais profissionais são igualmente referência no que tange à prescrição do "bom gosto" alimentar.

25 Le lait cru est révélateur du terroir car il ne subit aucun traitement thermique et témoigne ainsi d'une vérité gustative, véritable reflet de l'adaptation de l'animal au sol, d'une part, et aux méthodes de fabrication mises au point au fil des années par les hommes, d'autre part. La transformation du lait cru est très sensible et ne supporte 
Na França, grande parte dos queijos AOC é de leite cru. Segundo o relatório de 2018 do Conseil National des Appellations d'Origine Laitière (CNAOL) ${ }^{26}$, entidade que congrega o conjunto de organismos de representação dos selos AOC, 76,4\% do total da produção de queijos AOC foram fabricados a partir do leite cru. Já os métodos oriundos do modelo produtivista que prioriza uma produção intensiva e industrializada são foco de diversas críticas.

Esse contexto de europeização dos selos AOC reflete em, pelo menos, dois processos fundamentais. No que se refere ao viés da produção, uma série de disputas relacionadas aos critérios produtivos foram desencadeadas, principalmente aquelas que remetem aos "standards nacionais". No que tange aos projetos de pesquisa e desenvolvimento, tanto o processo de densificação como a harmonização das normas sanitárias fundamentaram parte relevante das pesquisas realizadas na região da Auvergne. Nesse sentido, o lugar de convergência desses dois processos está na disputa pela justificação da singularidade de cada queijo AOC.

O período de densificação estimulou uma série de pesquisas voltadas para o fomento e apoio da implementação dos critérios produtivos surgidos nesse contexto. Ainda que a participação da expertise científica não seja inédita, nem tampouco exclusiva para as justificar tais critérios, ela aponta para contornos especialmente interessantes no contexto de europeização das AOC: incorpora-se nesse período de densificação uma preocupação com a produção no que diz respeito à qualidade do leite, como será descrito adiante.

\section{A EXPERTISE CIENTÍFICA E A SINGULARIDADE DOS QUEIJOS $A O C$}

"Silicon Valley dos queijos" é o título dado pelo jornal local La Montagne às organizações de pesquisa e desenvolvimento que estão na Rue de Salers, na pequena cidade de Aurillac, região da Auvergne ${ }^{27}$. Reunindo cinco instituições dedicadas à qualificação da produção de leite e queijos na região, entre laboratórios de pesquisa, análise e formação, essa rua não se

pas la médiocrité. Elle offre un rendu gustatif incomparable et une profonde richesse aromatique.

26 Conselho Nacional de Denominações de Origem Leiteiras.

27 O jornal regional La Montagne é quem faz essa relação entre Silicon Valley e Rue de Salers. Disponível em: https://www.lamontagne.fr/auvergne/actualite/departement/cantal/aurillac/2013/11/11/\%20la-route-desalersabrite-un-reseau-dentreprises-et-de-laboratoires-de-pointe-dansleur\%20domaine_1760494.html. Acesso em: 15 maio 2014. 
encontra num vale, mas no topo de uma ladeira e, por esse motivo, também é conhecida como a "colina queijeira de Aurillac". Ultrapassando as competências dos organismos representativos dos agricultores e produtores vinculados às $\mathrm{AOC}$, os queijos da região são defendidos por uma verdadeira estrutura científica voltada para o desenvolvimento da produção do leite e queijo. Uma das questões suscitadas frente a todas essas organizações é qual o papel das pesquisas científicas para a produção de queijos considerados tradicionais. Levando em consideração que o conhecimento científico é evocado geralmente para atestar a eficiência e a inocuidade das inovações na produção agroalimentar, é oportuno compreender qual a relação entre a ciência e a produção de queijos que reivindicam seus métodos como artesanais e tradicionais.

Tendo em vista a amplitude do trabalho desenvolvido pelas instituições presentes na Rue de Salers, o artigo delimitará apenas algumas iniciativas presentes nas instituições dessa rua: a Unité des recherches fromagères do INRA ${ }^{28}$. Inaugurado em 1973, a unidade de pesquisa concentra atualmente seus trabalhos na área da microbiologia, sendo que a produção de queijos AOC feitos a partir do leite cru é tema central das pesquisas. Marie-Christine Montel, enquanto diretora da unidade de pesquisa, foi uma das principais interlocutoras durante a pesquisa de campo.

Reconhecida pelos seus trabalhos ligados à ecologia microbiana dos queijos, Montel é também uma militante dos queijos de leite cru. Junto ao movimento Slow Food ${ }^{29}$, Montel mantém uma importante interlocução. Em 2008, a pesquisadora conferiu uma palestra na universidade de verão do movimento, cujo foco foi dedicado ao tema ${ }^{30}$. Ao seu lado, personalidades importantes do campo produtivo dos queijos: André Valandier, fundador da cooperativa Jeune Montgne, a única que produz o AOC Laguiole; Patrice Chassard, na época presidente da AOC Saint-Nectaire.

Como conferencista, Marie-Christine Montel também acumula participações em eventos do mundo profissional, a exemplo das suas palestras por dois anos consecutivos na Journée

\footnotetext{
28 Unidade de pesquisas sobre queijos do Instituto Nacional de Pesquisa Agronômica.

29 O movimento Slow Food nasceu nos anos 1980 como uma associação pela defesa do prazer à mesa e atualmente se identifica como um movimento internacional que critica o modelo agroalimentar e a luta pela preservação da biodiversidade, sendo os queijos de leite cru uma de suas principais pautas. Diferentes grupos se organizam em torno desse movimento, ressalto personalidades ligadas à gastronomia, acadêmicos etc. Para maior aprofundamento sobre o Slow Food na França, ver Garcia-Parpet (2016).

$30 \mathrm{O}$ evento foi organizado por um convívio, ou seja, um grupo regional do movimento. O tema foi inteiramente dedicado aos queijos de leite cru. Para mais informações, ver: http://www.agrisalon.com/fr/actualites/agroalimentaire/article/3873590/Slow-Food-France-consacre-son-Universite-d-ete-au-lait-cru.html Acesso em: 14 outubro de 2014.
} 
Tecnhique da revista Profession Fromager ${ }^{31}$. No seu currículo, a pesquisadora ainda aparece como jurada em alguns concursos de premiação de queijos, como o Farm Cheese Awards realizado pela associação francesa Fromages de Terroirs. Para além da França, Montel também foi convidada para os eventos da renomada queijaria inglesa Neal's Yard Dairy - sendo que a sua pesquisa sobre a microflora do leite cru foi traduzida para o inglês por conta da iniciativa da coordenadora de compras e gerente técnica dessa queijaria.

A formação de Marie-Christine Montel se deu principalmente na região, com a graduação na Universidade de Blaise-Pascal em Clermont-Ferrand e a tese em Ciência da Alimentação já sob a tutela institucional do INRA. Ela conta que foi contratada pela instituição antes mesmo de terminar a sua tese, pois era uma época em que o INRA recrutava muitos profissionais e se interessava em desenvolver a área de pesquisa em alimentos. Foi com os projetos sobre o papel da biodiversidade microbiológica na qualidade sanitária e organoléptica dos queijos de leite cru que Montel alcançou maior reconhecimento. Dentre seus trabalhos de maior relevância, destacam-se as pesquisas sobre microrganismos que realizam um efeito barreira contra bactérias patogênicas nos queijos de massa prensada e de leite cru. $\mathrm{O}$ argumento que fundamenta tais pesquisas parte do pressuposto que leite cru pode, através da interação microbiana, desempenhar um papel de obstáculo para o crescimento de patógenos. Nessa perspectiva, a pasteurização do leite não é recomendada, pois uma vez contaminado depois da pasteurização, o leite não apresentaria nenhum bloqueio bacteriano. Esse estudo se desenvolveu em grande medida com a inibição da Listeria nos queijos AOC Saint-Nectaire.

Marie-Christine Montel chega na direção do INRA em 2000, época que coincide com a revisão dos cadernos de especificações técnicas dos queijos AOC da região. É nesse período de europeização do selo AOC que surge o interesse em desenvolver pesquisas focalizadas na produção de leite. Para tanto, o INRA, sob a direção de Marie-Christine Montel, disponibiliza uma vaga de estágio para um funcionário da Câmara de Agricultura ${ }^{32}$ da região do Cantal. A abertura dessa vaga parte da consideração que nenhum funcionário da Câmara de Agricultura, mais próxima da extensão rural, tinha formação na área da microbiologia. Segundo Montel:

31 As jornadas técnicas da revista Profession Fromager são eventos anuais voltado para um público de profissionais da área, principalmente para queijeiros que buscam o nicho do mercado de qualidade. Nos dois anos em que pude acompanhar a apresentação de Montel o tema foi sobre queijos de leite cru.

32 Em francês, chambre d'agriculture. Sem um paralelo com instituições brasileiras, as Câmaras de Agricultura na França são instituições públicas cuja direção é eleita pelo voto de organizações de representação de agricultores. O trabalho das Câmaras de Agricultura se baseia na gestão de alguns subsídios públicos voltados a agricultura, como também na extensão e no desenvolvimento rural. 
É justamente com a colaboração da Câmara de Agricultura que tentamos trabalhar com esses aspectos de onde vem a microflora do leite para poder agir mais a montante e tentar preservar a diversidade que colocamos em evidência no ubre da vaca, é um reservatório [microbiológico] e se temos práticas que são muito higienistas, no sentido de não se preocupar com a diversidade, bah, se ela não se preocupar não teremos mais diversidade. Então, de acordo com as práticas muito higienistas, como lavagem da ordenhadeira mecânica, ou práticas mais ou menos higienistas, iremos ter perfis microbianos que vão ser diferentes sobre a ordenha e depois sobre o leite ${ }^{33}$

Essa parceira Câmara de Agricultura e INRA demonstra uma conversão importante ocorrida nesta regional do instituto. Segundo Montel, antes da sua chegada à diretoria, as pesquisas tinham como foco a otimização tecnológica e a busca por bactérias que pudessem remediar os efeitos causados por práticas que ela considera higienistas. Eram as chamadas pesquisas com os fermentos. A microbiologista propõe então valorizar outras formas de manipular o leite para não afetar o que ela diz ser a diversidade microbiológica dos queijos. O leite ganha outro status, o de detentor da diversidade, o que lhe garante uma maior pertinência no argumento que sustenta a patrimonialização da produção de queijos.

Da parceria com a Câmara de Agricultura surgiu, em 2011, o "FlorAcq - projeto de apoio aos produtores de leite para orientar equilíbrio microbiano do leite para a qualidade dos queijos de leite cru" ${ }^{34}$. Reunindo entidades de caráter técnico e científico, o projeto FlorAcq criou uma metodologia de acompanhamento dos produtores para orientar e valorizar o equilíbrio microbiano dos queijos de leite cru. O objetivo era, a partir dessa metodologia, modificar as práticas dos produtores para uma melhor gestão da flora presente no leite cru.

O pressuposto é que regulamentações sanitárias incentivaram práticas higienistas que, associadas ao processo de transformação industrial, resultaram num empobrecimento da flora microbiana presente no leite. Tais práticas incorreram numa padronização do sabor nos queijos. O leite cru, ao contrário, é visto pela sua capacidade de preservação das especificidades do produto, pelo seu estimado valor sensorial e, sobretudo, por representar o vínculo ao terroir. Por

33 Justement avec la collaboration de la chambre de l'agriculture on a essayé de travailler sur ces aspects, d'où vient la microflore de lait pour pouvoir agir plus en amont et essayer de préserver cette diversité et on a mis en évidence le trayon de vache c'est un réservoir et si on a des pratiques qui sont beaucoup trop hygiéniste dans le sens qui ne soucient pas de la diversité, bah si elles ne soucient pas, on n'aura pas de la diversité. Donc, selon des pratiques très hygiénistes, lavage de trayon, moyennement hygiéniste ou plus hygiéniste on va avoir des profils microbienne qui vont être différents sur le trayon et puis dans le lait. (DIARIO DE CAMPO, 2015).

34 FlorAcQ - démarche d'accompagnement des producteurs de laits pour orienter les équilibres microbiens des laits en faveur de la qualité des fromages au lait cru". Montel participou de diversos projetos cujo tema foram os queijos de leite cru, a apresentação somente desse projeto deve-se ao limite de espaço para discussão. 
esse viés, a originalidade dos queijos de leite cru depende muito das comunidades microbianas presentes no leite. Os microrganismos tornam-se, dessa maneira, a singularidade de cada produto.

O projeto de elaboração de uma metodologia de valorização de boas práticas na produção do queijo de leite cru possui a perspectiva de produção de conhecimento concomitante à proposta de intervenção em práticas, tal como na extensão rural. Outros tantos projetos realizados nas instituições da Rue de Salers, na cidade de Aurillac, possuem essa dupla perspectiva. Tal descrição tem como objetivo identificar a forma pela qual a expertise científica oriunda desses organismos desenvolveu conhecimentos científicos e instrumentos técnicos capazes de atender aos critérios que surgiram no período de internacionalização dos selos.

No momento em que foi necessário legitimar o estatuto privilegiado dos selos AOC frente às negociações europeias, houve uma participação efetiva de pesquisas, além da elaboração de técnicas que pudessem legitimar o caráter tradicional da produção de queijo. Se a pesquisa na área agroalimentar é, frequentemente, vinculada à inovação, nesse caso específico ela remete ao intuito de identificar e valorizar aquilo que se reconhece como tradicional.

Nessa perspectiva, o foco principal desloca-se para a produção do leite e ele se torna a matéria-prima capaz de auferir singularidade aos queijos AOC. No esforço de "tradução do terroir" foi necessário criar parâmetros que pudessem demonstrar a autenticidade dos produtos. $\mathrm{O}$ leite ganha em importância e os microrganismos a originalidade dos queijos. Elementos dessa natureza criam uma narrativa em torno dos queijos capaz de reposicioná-los dentro do circuito da produção e do consumo alimentar.

O leite cru encarna a biodiversidade que deve ser preservada e consegue "traduzir" o vínculo com o terroir. Como prescrições no processo produtivo, o projeto sobre a biodiversidade do leite cru reflete uma classificação de determinadas práticas produtivas em detrimento de outras - algumas são valorizadas, outras são depreciadas. De certa forma, a expertise científica participa da elaboração de critérios que pretendem conferir maior singularidade aos queijos.

Para o presente artigo é eloquente mencionar a incorporação do projeto FlorAcQ na grade do currículo formal dos estudantes do colégio agrícola e da Escola Nacional de Industrias de Lácteos (ENIL). Assim, a metodologia de acompanhamento da produção visando encontrar um equilíbrio microbiano dos queijos de leite cru tornou-se o tema de um módulo da educação formal dentro do ensino agrícola na França.

Um breve histórico de instalação das instituições de educação na Rue de Salers identifica que a primeira que se estabeleceu nessa rua foi a Escola Nacional de Agricultura e Laticínios, cujas portas foram abertas em 1909, na cidade de Aurillac. Em 1930 essa escola tornou-se 
Escola Nacional da Indústria de Lácteos (ENIL), reforçando o processo de industrialização vivenciado na região durante esse período. No fim da década de 1960, num esforço do Estado francês em criar as bases do ensino agrícola e acompanhar a modernização da agricultura, o Colégio Agrícola Georges Pompidou ${ }^{35}$ se juntou ao ENIL de Aurillac.

A incorporação do projeto sobre a microbiologia do leite cru revela o incentivo à integração de determinados conhecimentos no currículo da educação formal. Considerando que a preocupação relativa à ecologia microbiana do leite do cru na qualidade do organoléptica do queijo são objeto de projetos científicos fomentados a partir do período de internacionalização dos selos AOC, tal exemplo demonstra um interesse na disseminação de tais conhecimentos e na transferência de seus instrumentos técnicos. Dessa forma, o período de internacionalização dos selos repercutiu como uma requalificação dos queijos a partir da enunciação de determinados critérios. Tais parâmetros, visando legitimar a qualidade superior dos produtos de origem protegida, se tornaram objetos de pesquisa e, mais recentemente, buscam adentrar nas vias de ensino formal.

\section{CONSIDERAÇÕES FINAIS}

Tendo como recorte o período de internacionalização das denominações de origem para território europeu, o presente artigo buscou retraçar as estratégias de legitimação de tais certificações através da incorporação de "novos" critérios produtivos para fabricação de queijos. A expansão das AOC para além das fronteiras francesas resultou numa configuração particular para a produção dos queijos. Enquanto os primeiros selos eram vagos, esforçando-se na proteção do nome do produto e na delimitação de uma zona geográfica de produção, o período de internacionalização fomentou uma série de "novos" critérios produtivos. Num momento em que as denominações de origem foram acusadas de ocuparem um espaço privilegiado nas negociações comerciais para o estabelecimento do livre comércio, foi necessário legitimar o cerne que fundamenta os selos AOC, a saber, a qualidade diferenciada de um produto por conta de sua origem de produção. Em outras palavras, foi preciso justificar a qualidade baseada no terroir.

Conhecido como um período de densificação nos cadernos de especificações técnicas,

$35 \mathrm{Na}$ França, o Lycée corresponde ao ensino secundário que se situa entre o fim da escola primária e o começo do ensino superior. O ensino secundário pode ser técnico ou profissional e, no caso do Lycée Georges Pompidou, trata-se do ensino profissional agrícola. 
esse momento incentivou a produção de queijos de leite cru através do argumento de preservação da diversidade sensorial, gustativa e cognitiva do terroir. Como uma espécie de prescrição para o conjunto de queijos franceses sob a tutela de uma AOC, tais critérios foram enunciados como balizas capazes de oferecer legitimidade à posição favorável que ocupam as denominações de origem frente a outros produtos no mercado. Esse processo resultou na categorização dos queijos e sua consequente qualificação - aqueles que acatavam as prescrições eram considerados mais "fiéis" ao seu terroir, enquanto aqueles que destoavam se distanciavam do que é considerado autêntico.

A adoção a esses "novos critérios" não foi automaticamente colocada em prática. A pesquisa de campo revelou uma estrutura científica bem estabelecida capaz de requalificar o risco sanitário ${ }^{36}$ : enquanto alguns consideram queijos não pasteurizados como uma ameaça, as pesquisas realizadas na Auvergne certificam métodos que garantem a inocuidade do leite cru, permitindo assim a sustentação do que é considerado uma fidelidade do produto ao seu terroir.

A implicação dos conhecimentos científicos não é recente e tampouco foi agenciada somente a partir da internacionalização dos selos. A obra de Gilles Laferté (2006), ao tratar da institucionalização da qualidade dos vinhos da Borgonha, bem como de sua redefinição simbólica, demonstra o quanto os conhecimentos oriundos da geografia foram incorporados no discurso oficial visando fornecer argumentos legítimos para a requalificação do território enquanto produtor de vinhos de qualidade. A pesquisa de campo na Auvergne identifica outras disciplinas científicas, não necessariamente vinculada às ciências humanas, que também se engajam nesse processo de categorização e qualificação das mercadorias. O trabalho de Marie-Christine Montel e sua equipe revela o quanto a microbiologia e, em particular, a ecologia microbiana é um conhecimento atuante na disseminação de critérios qualificadores dos produtos que podem ser identificados a partir da referência ao terroir.

Das pesquisas incentivadas a partir da europeização dos selos, determinados conhecimentos passaram, posteriormente, a ser transferidos enquanto instrumentos técnicos. Tipologias e métodos para o acompanhamento de produtores e formações foram incentivados e promovidos. Mais recentemente, há um esforço que visa transferir tais conhecimentos às estruturas da educação formal. Dessa forma, a pesquisa de campo pode identificar como uma parte da expertise científica da região engajou-se na disseminação de certos insumos, métodos e instrumentos legitimados como artesanais e tradicionais.

36 Embora o presente artigo não tenha aprofundado nesse tema, é relevante que uma série de outros atores ligados às instituições públicas, à gastronomia e aos movimentos da sociedade civil participaram desse processo. 
Embora o conhecimento científico e a produção alimentar estejam historicamente muito próximos, a pesquisa de campo revelou um caso em que a expertise científica foi chamada para atestar insumos e métodos considerados tradicionais. A relação entre microbiologia e indústria do leite não é novidade, embora o conhecimento científico seja mais frequentemente convidado a atestar a inovação no lugar da tradição. Desde o nascimento da disciplina científica da microbiologia se observa um movimento transversal do laboratório à indústria, da pesquisa fundamental para a pesquisa aplicada (VATIN, 1990). A presente pesquisa quis ressaltar que, embora as demandas sejam diversificadas e os critérios propostos diferenciados, a produção alimentar apela reiteradamente às disciplinas e práticas científicas, seja qual for o viés de qualidade sustentado. Ademais, independentemente do modelo a ser apoiado, o conhecimento científico parece jamais ser totalmente desinteressado.

\section{REFERÊNCIAS}

1. BERTUSSI, M. L. A qualidade dos queijos da região da Auvergne: um estudo sobre as relações entre a expertise científica e o fomento das appellations d'origine contrôlée (aoc). 2020. 257 f. Tese (Doutorado) - Curso de Antropologia Social, Instituto de Filosofia e Ciências Humanas, Universidade Estadual de Campinas em Cotutela Com École Des Hautes Études En Sciences Sociales, Campinas, 2020. Cap. 4.

2. BARHAM, E. Translating Terroir: The Global Challenge of French AOC Labeling. Journal of Rural Studies, v. 19, n. 1, p. 127-138, 2003. Disponível em: https://www. sciencedirect.com/science/article/abs/pii/S0743016702000529?via\%3Dihub Acesso em: 05 de julho de 2021.

3. BOLTANSKI, L.; ESQUERRE, A. Enrichissement: une critique de la marchandise. Paris: Gallimard, 2017.

4. BOURDIEU, P. Le marché des biens symboliques. L'Année Sociologique, Paris, v. 22, n. 3, p. 49-126, 1971. Disponível em: https://www.jstor.org/stable/27887912?seq=1\#page_ scan_tab_contents. Acesso em: 14 mar. 2016.

5. BOURDIEU, P. Le champ scientifique. Actes de La Recherche En Sciences Sociales, v. 2, n. 2, p. 88-104, 1976. Disponível em: https://www.persee.fr/docAsPDF/arss_03355322_1976_num_2_2_3454.pdf. Acesso em: 15 out. 2015.

6. CASABIANCA, F.; VALCESCHINI, E. (éd.). La qualité dans l'agroalimentaire: émergence d'um champs de recherche. Rapport final. Paris: INRA-SAD, 1996. 344 p. (AIP Construction social de la qualité). 
7. CNAOL (França). Institut National de L'Origine Et de La Qualité. Chiffres clés 2019: des produits sous signes de la qualité et de l'origine produits laitiers aop et igp. Paris, 2020. 12 p. Disponível em: https://www.fromages-aop.com/wpcontent/uploads/CnaolChiffres-Cles-2019.pdf. Acesso em: 15 out. 2020.

8. DELFOSSE, C. L'intégration à l'INAO d'un autre secteur AOC développé: les produits laitiers. In: WOLIKOW, S.; HUMBERT, F. Une histoire des vins et des produits AOC: l'Inao de 1935 à nos jours. Dijon: Presses Universitaires de Dijon, 2015. p. 161-180.

9. GARCIA-PARTET, M-F. Le marché d'excellence. Les grands crus à l'épreuve de la mondialisation. Paris: Seuil, 2009.

10. GARCIA-PARTET, M-F. Valorização dos produtos locais e mundialização dosmercados. In: MARQUES, F. C.; CONTERATO, M. A.; SCHNEIDER, S. Construção de mercados e agricultura familiar: desafios para o desenvolvimento rural. Porto Alegre: Editora da UFRGS, 2016. p. 159-181.

11. LAFERTÉ, G. La Bourgogne et ses vins: image d'origine contrôlée. Paris: Belin, 2006.

12. DUBOIS, L. La vie d'un fromage. 2020. Disponível em: http://www. fromageslaurentdubois.fr/fr/savoir-faire.html. Acesso em:10 out. 2020

13. MONSALLIER, F. FlorAcq: Démarche d'accompagnement des producteurs de laits pour orienter les équilibres microbiens des laits en faveur de la qualité des fromages au lait cru. Aurillac: Chambre D'agriculture Du Cantal, 2014. (Projet CASDAR FlorAcq 2011-2014).

14. OLIVIER, J.; LAFERTÉ, G. Le contrôle républicain du marché. Vignerons et négociants sous la Troisième République. In: HISTOIRE, SCIENCES SOCIALES, 61., 2006, Paris. Annales... Paris: Éditions de 1'EHESS, 2006. p. 1147-1170.

15. VABRE, S. Le sacre du Roquefort: l'émergence d'une industrie agroalimentaire. Tours: Presses Universitaires François-Rabelais de Tours, 2015.

16. VATIN, F. L'industrie du lait: Essai d'histoire économique. Paris: L'harmattan, 1990.

\section{Mayra Lafoz Bertussi}

Doutora em Ethnologie et Anthropologie Sociale pela École des Hautes Études en Sciences Sociale em cotutela com o Programa de Pós-Graduação em Antropologia Social da Universidade Estadual de Campinas. Mestrado em Ethnologie et Anthropologie Sociale pela École des Hautes Études en Sciences Sociale (2014), Mestrado em Antropologia Social pela Universidade Federal do Rio Grande do Sul (2010) e Graduação em Ciências Sociais pela Universidade Federal do Paraná (2005). ID ORCID: https://orcid.org/0000-0002-2366-1376. E-mail: mayralafoz@ gmail.com. 